\title{
PRELIMINARY ESTIMATION ON POINTING ACCURACY OF JAPANESE QUASI-ZENITH SATELLITE-1 (MICHIBIKI) L1-SAIF
}

\author{
Mitsuharu Tokunaga, Yuta Nagaoka, Tatsuya Shoda \\ Dept. of Civil and Environmental Engineering, Kanazawa Institute of Technology, Nonoichi, Ishikawa 921-8501, \\ Japan mtoku@neptune.kanazawa-it.ac.jp
}

Commission I, WG I/5

KEY WORDS: GNSS, QZS, MICHIBIKI, L1-SAIF, NAVIGATION, GPS

\begin{abstract}
:
Japanese Quasi-Zenith Satellite-1 (QZS1) named MICHIBIKI was launched in September, 2010. This paper shows a preliminary estimation of positioning accuracy of the QZS1. The mission of QZS1 is to raise the positioning accuracy of GPS. The QZS1 has 3 positioning signals named LEX, L1-SAIF and L1-CA. LEX and L1-SAIF are auxiliary signals based RTK and differential measurement using revised information derived from the electronic reference points managed by the Geographic Survey Institute of Japan respectively. QZS1 L1-SAIF signal is expected the accuracy less than $1 \mathrm{~m}$. In order to estimate the positioning accuracy of QZS1 L1-SAIF, the positioning accuracy of QZS1 were compared with the accuracy of GPS single measurement. As the results, for an example, GPS accuracy is $3.17 \mathrm{~m}$ in latitude and $3.90 \mathrm{~m}$ in longitude, and L1-SAIF accuracy is $1.68 \mathrm{~m}$ and $1.80 \mathrm{~m}$ respectively. This result indicates L1-SAIF provides high accuracy than GPS. But others result showed, GPS accuracy is $1.57 \mathrm{~m}$ in latitude and $1.26 \mathrm{~m}$ in longitude and L1-SAIF accuracy is $4.03 \mathrm{~m}$ and $0.92 \mathrm{~m}$ respectively. Conclusions are; (1) L1-SAIF signal were obtain submeter accuracy. (2) Almost L1-SAIF signal were obtained high accuracy better than GPS. (3) In worst case, L1-SAIF signal were obtained worse accuracy than GPS. The reason is assumed the influence of the East Japan tremendous earthquake. As the electronic reference points were moved by the earthquake, the reinforcement value derived from the electronic reference points might be incorrect.
\end{abstract}

\section{INTRODUCTION}

GPS signals are interrupted by a building in urban area and a mountain slope. Therefore, the GPS positioning is not available in all places. In order to expand of GPS positioning area and raise positioning accuracy, the MICHIBIKI satellite was launched in September 2010. The MICHIBIKI satellite passed near the zenith in Japan and transmitted the almost same signal as GPS. Therefore, it is expected expansion of the use possible area and the increase in utility time. Moreover, MICHIBIKI satellite can correct the error caused by lonosphere delay and watervapour though cooperate with ground stations. It is also expected to improve the positioning accuracy. It is necessary to prove that MICHIBIKI satellite can be positioning in the accuracy according to the design, carry out evaluation accuracy after carry out an experiment in this research.

\section{THE FEATURE OF THE MICHIBIKI SATELLITE}

There are two kinds of signals of the MICHIBIKI satellite, a LEX signal and an L1-SAIF signal. LEX signal is called centimeter class that is expected in the positioning ability of centimeters of accuracy. L1-SAIF signal is called sub-mater class that is expected in the positioning ability of one meters of accuracy. The MICHIBIKI satellite has some features in raising accuracy. To receive the satellite signal easily, which is designed to pass the zenith parts of the Japan while draw the figure eight of orbit. So it is called Quasi-Zenith Satellite. Moreover, in order to improve the positioning accuracy of GPS, it has the performance of a complement and reinforcement.

\subsection{The role of a complement}

To MICHIBIKI satellite sends the signal almost the same as GPS signal, which enables MICHIBIKI satellite to be used as GPS satellite. Thereby, a positioning possible hour rate will be expected $99.8 \%$ from about $90 \%$. Satellite covers the country without interruption to shield, which can increase available time and can be positioning highly accurate. However, time to stay over Japan is restricted within 8 hours. Quasi-Zenith Satellite of least two aircraft is required for 24 hour operation. The complement improves of observation area. But it is not expected to improvement in accuracy.

\subsection{The role of reinforcement}

Reinforcement has worked to improve the error caused by the influence of the ionosphere and troposphere called to propagation of errors receives location information from the positioning satellites. This structure corrects the error produced in the ionosphere or the troposphere, When a ground station transmits the information on the electronic reference point where known as the true position is carried out to a satellite. The reinforcement can expect the high accuracy of less than 1 meter called the sub-meter class.

\section{VERIFICATION}

The purpose of this research is to perform accuracy evaluation of an L1-SAIF signal. In order to verify positioning accuracy, two kinds of averages standard deviations, and the maximum error from GPS single positioning and L1-SAIF (reinforcement) is evaluated.

\section{EXPERIMENT METHOD}

4.1 Development of MICHIBIKI signal receiving System 
The system used by this research is developed by the following. Hardwere;

- PDA HP iPAQ112 (Windows Mobile6)

- QZS Receiving antenna provided by SPAC

Software;

- Data Logger Software developed by authors

-QZS ProveTool provided by AISAN Technology

\subsection{The measurement method}

The positioning accuracy of QZS1 L1-SAIF were measured with one of only GPS at same place and time, on condition of on a fixed point, on a walk and on a high-speed movement.( figure $1,2,3$ )

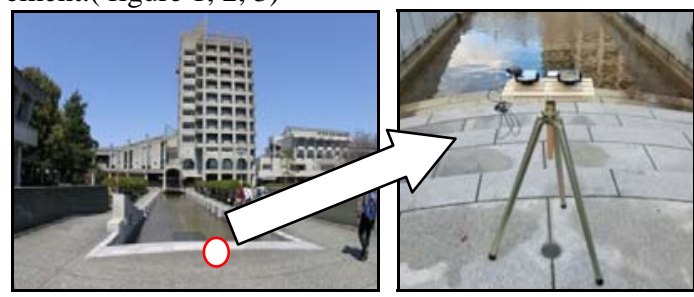

Figure 1. a fixed point and devices

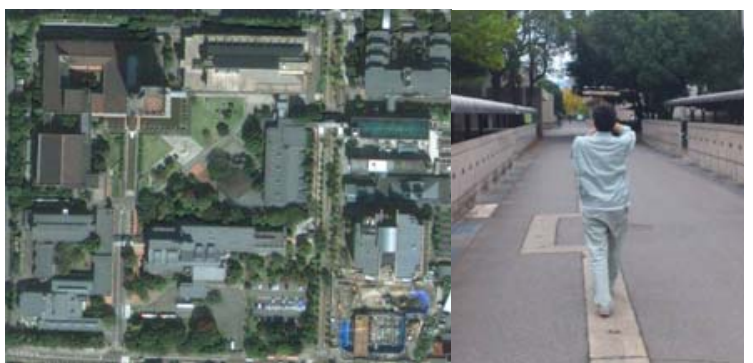

Figure 2. place on a walk and devices

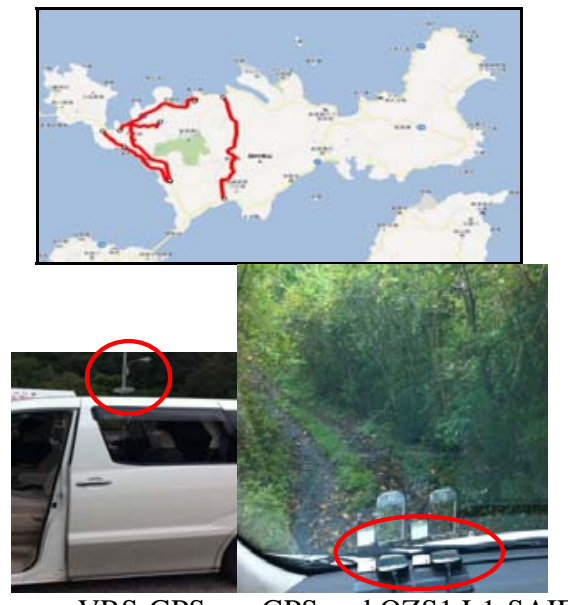

VRS-GPS

GPS and QZS1 L1-SAIF

Figure 3. observation area and devices

\section{RESULTS}

The measurements of the fixed point data on March 31 is shown in figure 4. A horizontal axis is latitude and a vertical axis is longitude and the unit is meter. Positioning data from the morning of March 31, the result brought that the accuracy of L1-SAIF is higher than the accuracy of GPS. Conducted measurements from March to April, 10:00a.m.to 11:00a.m. MICHIBIKI satellite passes near the zenith of Japanese. So L1-SAIF became highly accurate than GPS.
However, L1-SAIF can't receive accuracy of sub-meter class in these results. Positioning data in the afternoon of March 31 did not have difference in the accuracy between GPS and L1SAIF.At Figures GPS and L1-SAIF in the morning and afternoon, movements of GPS and L1-SAIF are almost the same. So, the problem of the accuracy is not a problem receiver of the GPS satellite.

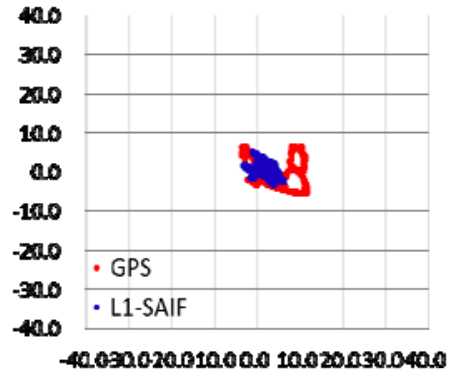

Figure 4. Positioning trajectory on the fixed point March 31, 2011

Table 1. Accuracy (March 31, 2011) unit: meter

\begin{tabular}{|c|c|c|c|c|}
\hline & \multicolumn{2}{|c|}{ GPS } & \multicolumn{2}{c|}{ L1-SAIF } \\
\hline & $\mathrm{x}$ & $\mathrm{y}$ & $\mathrm{x}$ & $\mathrm{y}$ \\
\hline Average & 3.09 & 2.62 & 1.29 & 1.39 \\
\hline Standard deviation & 3.90 & 3.16 & 1.68 & 1.80 \\
\hline Maximum error & 11.65 & 6.51 & 5.02 & 6.29 \\
\hline
\end{tabular}

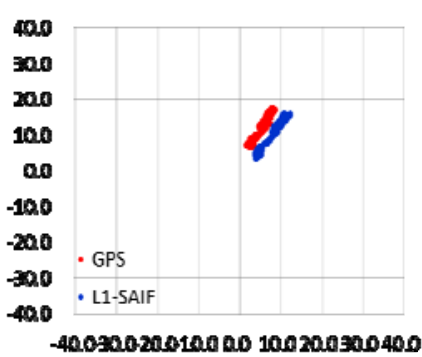

Figure 5. Positioning trajectory on the fixed point November 25, 2011 (Blue: GPS, Red: QZS1 L1-SAIF)

Table 2. Accuracy (November 25, 2011) unit: meter

\begin{tabular}{|c|c|c|c|c|}
\hline & \multicolumn{2}{|c|}{ GPS } & \multicolumn{2}{c|}{ L1-SAIF } \\
\hline & $\mathrm{x}$ & $\mathrm{y}$ & $\mathrm{x}$ & $\mathrm{y}$ \\
\hline Average & 6.95 & 8.65 & 4.44 & 10.49 \\
\hline Standard deviation & 2.64 & 3.99 & 1.88 & 3.30 \\
\hline Maximum error & 12.21 & 15.68 & 8.49 & 17.36 \\
\hline
\end{tabular}
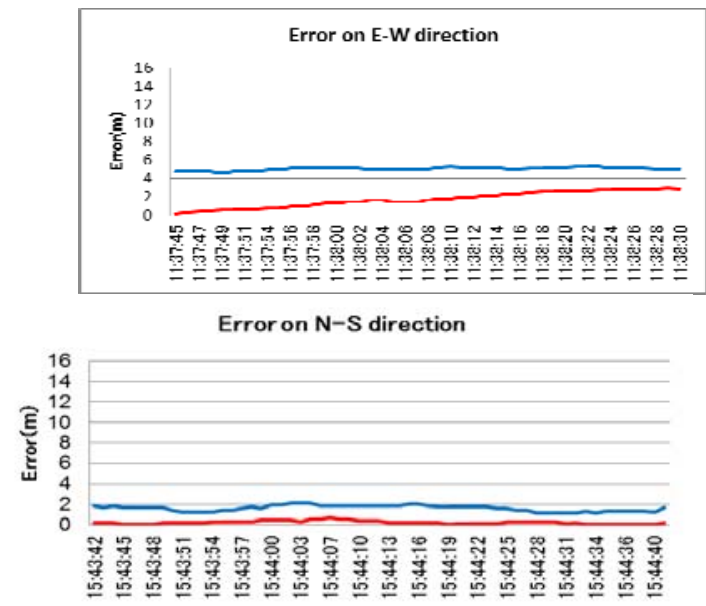

Figure 6. Positioning accuracy on a walk (Blue: GPS, Red: QZS1 L1-SAIF) 


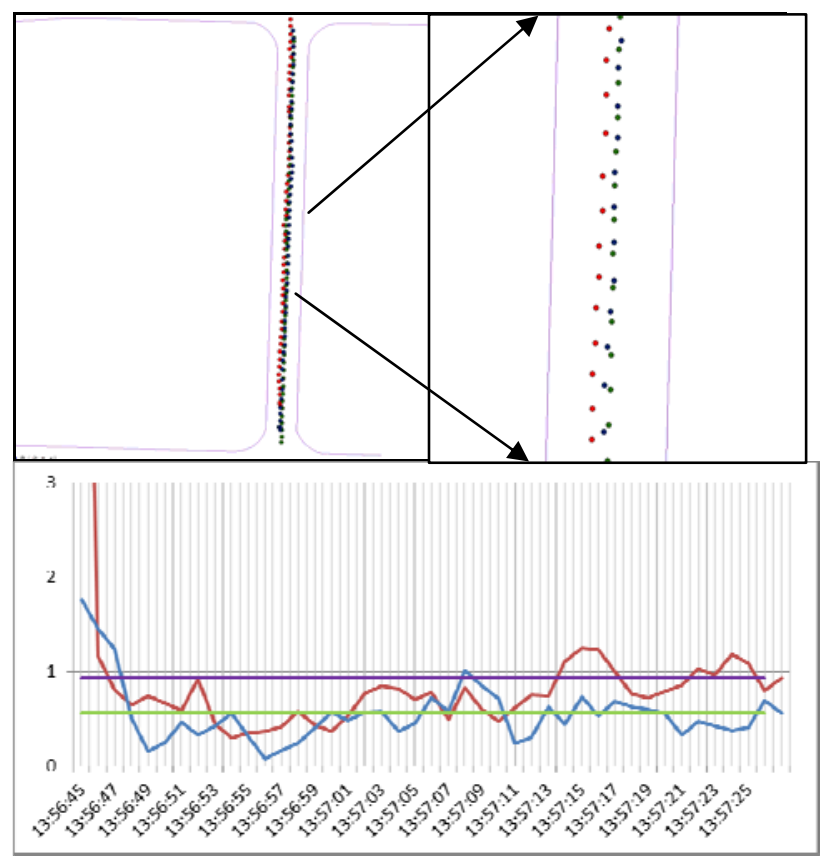

Figure 7. Comparre with GPS,QZS and VRS-GPS (Red: GPS, Blue: QZS1 L1-SAIF)
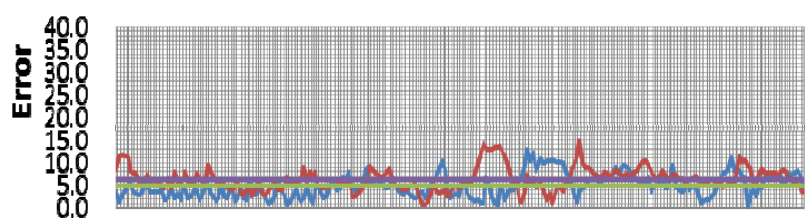

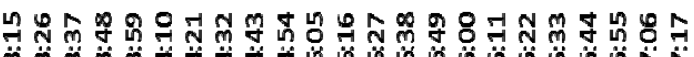

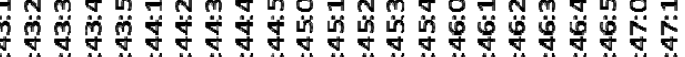

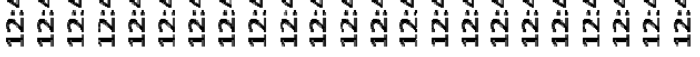
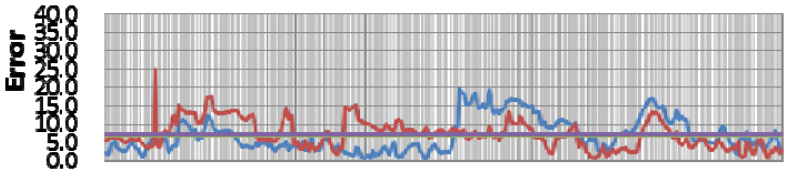

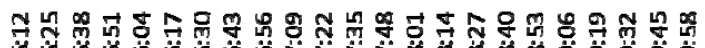

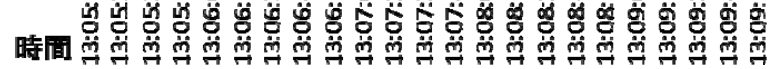
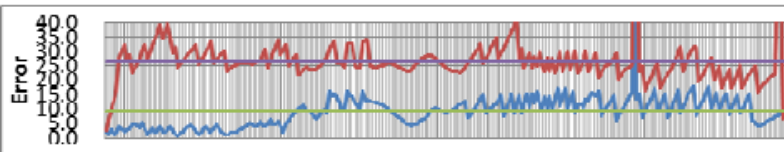

గ.

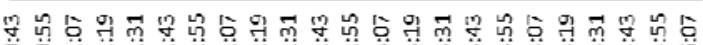

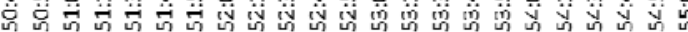

時弣

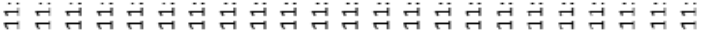

Figure 8. Positioning accuracy on a car

(Red: GPS, Blue: QZS1 L1-SAIF)

Table 3. Accuracy (unit: meter)

\begin{tabular}{|c|c|c|}
\hline & & \\
\hline Average & GPS & L1-SAIF \\
\hline Route1 & 6.35 & 4.93 \\
\hline Route2 & 7.23 & 7.00 \\
\hline Route3 & 26.47 & 9.10 \\
\hline
\end{tabular}

\section{CONCLUSIONS}

Accuracy evaluation of GPS and L1-SAIF were able to be verified in this research. The difference of the accuracy of L1SAIF by a time zone was seen from the result of this accuracy evaluation. When comparing GPS data and L1-SAIF data, morning data has higher accuracy. While the afternoon data does not show big difference between GPS and L1-SAIF.In addition, the result obtained from GPS is higher in accuracy than L1-SAIF on another day. For L1-SAIF signal send only the compensation data of propagation of errors, position information is obtained from GPS. However, due to PDA had received the L1-SAIF signal, it is thought that accuracy became low by the problem of arrangement of GPS. Considering the DOP value of a measured day, the DOP value in the morning was stabilized and was high. But the afternoon DOP value was unstable and the number of satellites also had fewer afternoons than the morning. Since this experiment used the electronic reference point of the Geographical Survey Institute, it was affected by the influence of an Eastern Japan tremendous earthquake which happened on March $11^{\text {th }}$ 2011.It is not taken the degree of the influence in this experiment. Measurement of a MICHIBIKI satellite will be continued from now on. And it is necessary that the accuracy of the reinforcement signal of a MICHIBIKI satellite become less than 1 meter

\section{FUTURE PLAN}

At the present stage, the receiving antenna of a MICHIBIKI satellite is using the $\beta$ - II version. This paper is only the rudiment evaluation step of MICHIBIKI satellite. MICHIBIKI receiving antenna( $\beta$-version II ) are manifestation the result in this paper. From now on, a MICHIBIKI receiving antenna (the $\beta$ - III version) will be provided from Satellite Positioning Research And Application center. To $\beta$-III version is considered multipath, which can expect improvement of accuracy higher than $\beta$ - II version.

\section{Acknowledgement}

This research was supported by Satellite Positioning Research and Application Center(SPAC).

\section{References}

[1] Tatsuya Shoda, Mitsuharu Tokunaga, Evaluation on Positioning Accuracy of MICHIBIKI Satellite L1-SAIF, The $32^{\text {nd }}$ Asian Conference on Remote Sensing, 2011, on CD-ROM

[2] JAXA QZS site; http://www.jaxa.jp/countdown/f18/ April 6.2011.

[3] SPAC QZS site;

http://www.eiseisokui.or.jp/ja/demonstration/about.php?PH PSESSID=065d94a5e3dda6d39224b2a3e4174174 April 6.2010.

[3]SPAC, “QZSR Driver and positioning API operation manual ”, October 29.2010 